\title{
O sujeito leitor e sua condição humana na abordagem do texto literário no ensino médio
}

Hiudéa Tempesta Rodrigues Boberga Rafaela Stopa ${ }^{b}$

\begin{abstract}
Resumo
$O$ artigo tem a finalidade de discutir algumas questões relacionadas ao fracasso do ensino da literatura na escola, notadamente para adolescentes, observando que o padrão tradicional pode e deve ser substituído por uma abordagem do tex to literário que priorize o envolvimento do sujeito leitor com sua leitura pessoal, que valorize suas impressões da leitura empreendida, à luz das novas teorias ainda tributárias da estética da recepção. Para ilustrar a proposta, apresenta-se uma sequência didática, que pode ser adequada ao trabalho docente, mesmo que ele ainda se prenda aos programas tradicionais vigentes.
\end{abstract}

Palavras-chave: Ensino de literatura; Sujeito leitor; Sequência didática.

b Professora assistente do CLCA - Uenp/Campus Jacarezinho. rstopa@uenp.edu 


\section{Introdução}

O que leva um jovem, em alguma etapa do seu crescimento, a se desinteressar pela leitura literária? Justo ele, que ainda criança se deixou embalar pelos contos infantis e buscou esse imaginário nos livros que tanto o fascinaram. Seria uma literatura que não mais lhe inspira? Questões de ordem financeira lhe impedem de priorizar a aquisição de livros? Passa por uma fase natural do seu desenvolvimento? Ou a atração por este mundo de fantasia é substituída por apelos mais interessantes e urgentes, como os prazeres da comunicação virtual? Se falta leitura literária na formação desses jovens, qual a parcela de responsabilidade da escola nesse processo?

Essas questões já inquietaram pais, professores, estudiosos da pedagogia da leitura, pesquisadores, e não apenas no Brasil, pois o desprezo pela leitura da literatura, entre aqueles que ingressam na adolescência, acentua-se em vários países, ao menos no mundo ocidental. É o caso, por exemplo, da crise verificada no ensino secundário de francês na última década. Disposto a confrontar o problema e buscando analisá-lo sob vários aspectos, Tzvetan Todorov logo detectou uma das causas dessa falha, ao consultar os programas oficiais e perceber que a orientação sobre o ensino da literatura vai em direção do "estudo da disciplina":

O conjunto dessas instruções baseia-se, portanto, numa escolha: os estudos literários têm como objetivo primeiro o de nos fazer conhecer os instrumentos dos quais se servem. Ler poemas e romances não conduz à reflexão sobre a condição humana, sobre o indivíduo e a sociedade, o amor e o ódio, a alegria e o desespero, mas sobre as noções críticas, tradicionais ou modernas. Na escola, não aprendemos acerca do que falam as obras, mas sim do que falam os críticos. (TODOROV, 2009, p. 26-27)

O modo como a literatura é tratada pela escola preocupa o autor, pois as obras são objeto apenas de ilustração de conceitos ou de novas metodologias de abordagem. Sem ignorar que esses instrumentos também podem enriquecer a percepção do literário, na justa medida do seu emprego como recurso complementar, Todorov lamenta não ser concedida ao leitor comum, que certamente não se dedicará aos exercícios da interpretação literária tal como ora se ocupam algumas disciplinas 
dos liceus, a oportunidade de experimentar simplesmente a sua condição humana no ato da leitura:

Em regra geral, o leitor não profissional, tanto hoje quanto ontem, lê essas obras não para melhor dominar um método de ensino, tampouco para retirar informações sobre as sociedades a partir das quais foram criadas, mas para nelas encontrar um sentido que lhe permita compreender melhor o homem e o mundo, para nelas descobrir uma beleza que enriqueça sua existência; ao fazê-lo, ele compreende melhor a si mesmo. (TODOROV, 2009, p. 32-33)

Sobre um dos perigos que a literatura corre no contexto cultural francês, observada a responsabilidade da escola, o autor ainda argumenta:

A literatura pode muito. Ela pode nos estender a mão quando estamos profundamente deprimidos, nos tornar ainda mais próximos dos outros seres humanos que nos cercam, nos fazer compreender melhor o mundo e nos ajudar a viver. [...] O leitor comum, que continua a procurar nas obras que lê aquilo que pode dar sentido à sua vida, tem razão contra professores, críticos e escritores que lhe dizem que a literatura só fala de si mesma ou que apenas pode ensinar o desespero. Se esse leitor não tivesse razão, a leitura estaria condenada a desaparecer num curto prazo. (TODOROV, 2009, p. 76-77)

E não é sem surpresa quando um dos mais engajados defensores do estruturalismo, distanciando-se dos tradicionais métodos que esta teoria inspirou, recomenda, para se buscar a "compreensão ampliada do mundo humano" ou o que mais pode provocar a leitura da literatura, que se deve

encorajar a leitura por todos os meios - inclusive a dos livros que o crítico profissional considera com condescendência, se não com desprezo, desde Os Três Mosqueteiros até Harry Potter: não apenas esses romances populares levaram ao hábito da leitura milhões de adolescentes, mas sobretudo, lhes possibilitaram a construção de uma primeira imagem coerente do mundo, que, podemos nos assegurar, as leituras posteriores se encarregarão de tornar mais complexas e nuançadas. (TODOROV, 2009, p. 82)

A linha de pensamento de estudiosos que se debruçam sobre o tema defende que se faz imperioso primeiramente haver leitores, para então se garantir que haverá leitores que estudarão literatura. Daniel Pennac, em Como um romance, já 
havia apresentado a necessidade de se resgatar nos jovens o desejo de voltar a ler, desde que fossem tocados essencialmente pelo prazer da fruição do texto e não pela obrigação imposta por qualquer circunstância:

Se, como se costuma dizer, meu filho, minha filha, os jovens não gostam de ler, ou melhor, não amam a leitura - e o verbo é justo, porque se trata de uma ferida de amor - não é preciso incriminar nem a televisão, nem a modernidade, nem a escola. Ou incriminamos tudo isso, se quisermos, mas somente depois de nos termos colocado esta primeira questão: o que foi que fizemos daquele leitor ideal, que ele era, naquele tempo em que representávamos, de uma só vez, o papel de contador e do livro? (PENNAC, 1998, p. 50, grifos no original)

Observe-se que o leitor "ideal" lembrado por Pennac já existiu "naquele tempo" da infância, portanto, já desfrutou de um prazer estético incorporado naturalmente na vivência familiar e no período de ingresso à escola, mas que foi perdido com o passar dos anos. São observações de um estudioso que defende a fruição do texto como estratégia a ser recuperada no ambiente escolar, e isso no contexto europeu dos anos 90.

Não é sem surpresa que resgatamos convicções muito parecidas, do poeta Carlos Drummond de Andrade, datadas dos anos 70, quando manifestou seu desalento ao constatar que a criança perde sua natural sensibilidade poética na escola, em vez de nela encontrar expedientes para cultivá-la:

Por que motivo as crianças, de modo geral, são poetas e, com o tempo, deixam de sê-lo? Será a poesia um estado de infância relacionada com a necessidade de jogo, a ausência de conhecimento livresco, a despreocupação com os mandamentos práticos de viver - estado de pureza da mente, em suma?

Acho que é um pouco de tudo isso, se ela encontra expressão cândida na meninice, pode expandir-se pelo tempo afora, conciliada com a experiência, o senso crítico, a consciência estética dos que compõem ou absorvem poesia.

Mas, se o adulto, na maioria dos casos, perde essa comunhão com a poesia, não estará na escola, mais do que em qualquer outra instituição social, o elemento corrosivo do instinto poético da infância, que vai fenecendo, à proporção que o estudo sistemático se desenvolve, até desaparecer no homem feito e preparado supostamente para a vida? 
[...] O que eu pediria à escola, se não me faltassem luzes pedagógicas, era considerar a poesia como primeira visão direta das coisas e, depois, como veículo de informação prática e teórica, preservando em cada aluno o fundo mágico, lúdico, intuitivo e criativo, que se identifica basicamente com a sensibilidade poética.

[...] Alguma coisa que se bolasse nesse sentido, no campo da Educação, valeria como corretivo prévio da aridez com que se costuma transcrever os destinos profissionais, murados na especialização, na ignorância do prazer estético, na tristeza de encarar a vida como dever pontilhado de tédio. E a arte, como a educação e tudo o mais, que fim mais alto pode ter em mira senão este, de contribuir para a adequação do ser humano à vida, o que, numa palavra, se chama felicidade? (ANDRADE, 1974, p.?)

A longa citação se faz necessária para que se possa colher, nos argumentos do poeta, as razões de sua preocupação com o banimento das experiências que a criança deveria usufruir, na escola, para lapidar seu "ser poético".

Há que se lembrar da literatura no quadro das artes, evocadas pelo poeta, responsáveis por este burilamento, afinal, no contexto dos currículos escolares, ela resultou em disciplina associada ao estudo da língua. Provavelmente, Drummond já pressentia o descaso do poder público e da sociedade emergente com a experiência do prazer estético, que em sua opinião também poderia ser absorvida pela escola. Nela deveriam estar os alicerces de uma formação mais humanizada e sensível. Neste campo, não é demais sempre recordar as lições de Antonio Candido em torno da função humanizadora da literatura, ainda atuais e indiscutivelmente estimuladoras quando confrontadas com as últimas proposições dos novos pesquisadores.

As ponderações aqui alinhavadas, e as implicações delas decorrentes, que tomam o seu curso ao longo de décadas de equívocos no campo das políticas educacionais, constituem o pano de fundo das reflexões que se pretende alcançar com este texto, especialmente sobre o espaço que o ensino de literatura ocupa e deve ocupar na formação do jovem leitor dentro da escola. A título de contribuição com a tarefa do professor, apresenta-se também uma sequência didática que busca valorizar as impressões de leitura do aluno, uma ilustração da abordagem que pode ser levada a efeito em sala de aula. 


\section{Brevíssimo percurso teórico-metodológico}

Quando se busca conhecer os fundamentos das ideias defendidas pelos estudiosos que se dedicaram ao tema do ensino da literatura no Brasil, encontram-se ao menos duas vertentes de publicações. A primeira, voltada para a deteç̧ão de graves problemas no trato do texto literário em sala de aula, com justificativas calcadas em pesquisas institucionais levadas a efeito na década de 80 e início de 90, a corroborarem os questionamentos levantados. Destacam-se, nessa perspectiva, autores pioneiros como Maria Thereza Fraga Rocco, Lígia Chiappini de Moraes Leite, Regina Zilberman, Tânia M. K. Rösing, Letícia Malard, Maria Alice Faria e Alice Vieira.

A segunda vertente, por sua vez, compreende a produção de autores que se dedicaram a propor metodologias de ensino, diante dos problemas levantados, buscando subsidiar os docentes com descrições de práticas pedagógicas ou sequências didáticas. Nesta categoria, surgiram publicações, ainda na década de 90 e início da seguinte, de pesquisadores e autores como Vera Teixeira de Aguiar e Maria da Glória Bordini, Nelly Novaes Coelho, Marisa Lajolo, Juracy Assman Saraiva, William Cereja e Rildo Cosson.

Mais recentemente, pode-se dizer que pesquisadores ligados a programas de pós-graduação stricto sensu, nas áreas de Letras e de Educação, fazem discípulos dedicados a produções que transcendem o âmbito acadêmico e ganham espaços especialmente junto aos docentes da educação básica. São autores como Graça Paulino, Zélia Versiani, Aracy Martins e Aparecida Paiva, ligadas ao Grupo CEALE/UFMG, ou José Hélder Pinheiro Alves, Maria Marta dos Santos Silva Nóbrega e Márcia Tavares da Silva (UFCG), ou ainda Alice Áurea Penteado Martha (UEM), Benedito Antunes e João Luís Cardoso Tápias Ceccantini (UNESP), José Nicolau Gregorin Filho e Neide Luzia de Rezende (USP), Flávia Brocheto Ramos e Cecil Jeanine Albert Zinani (UCS) e Maria Amélia Dalvi Salgueiro (UFES), para citar os pesquisadores mais atuantes.

Além de Antonio Candido e suas concepções sobre a literatura e a formação do homem, e de Hans Robert Jauss e Wolgang Iser, respectivamente defensores da estética da recepção e teoria do efeito, os pesquisadores brasileiros elegeram estudiosos franceses como suas fontes de investigação sobre as 
questões da leitura literária e ensino de literatura, compreendendo Roger Chartier, Anne-Marie Chartier, Michele Petit, Vincent Jouve, Annie Rouxel, além do belga Antoine Compagnon e da espanhola Teresa Colomer. Dentre os conceitos discutidos por esses autores, perpassam as ideias de se preservar a recepção do texto no ambiente escolar, valorizando-se as experiências de leituras subjetivas e o amadurecimento afetivo e emocional do leitor antes de sua submissão à leitura da literatura escolarizada. Um argumento de Annie Rouxel pode sintetizar a linha de pensamento dominante entre os estudiosos:

Pela leitura sensível da literatura, o sujeito leitor se constrói e constrói sua humanidade. Na abordagem didática da literatura enquanto arte, o campo das emoções é ainda pouco explorado e constitui inegavelmente uma via para pesquisas futuras. (ROUXEL, 2013, p. 32)

Embora tais conceitos tenham chegado a docentes da educação básica, em alguns estados brasileiros, cujas diretrizes curriculares oficiais foram atualizadas nos últimos anos, ainda está muito longe o dia em que de fato se dê o salto de qualidade da teoria à prática em sala de aula. Considerando-se o reduzido aproveitamento dessas ideias pela escola, o prejuízo recai sobre uma geração que se encontra à mercê de procedimentos convencionais de leitura literária, reconhecidamente toscos diante das potencialidades intelectuais e emotivas de estudantes que hoje vivem expectativas cada vez mais instigantes, inclusive provindas do mundo virtual.

\section{Literatura em sala de aula: a necessidade de se superar o modelo tradicional}

Em várias produções, os pesquisadores são unânimes em apontar a concepção vigente na escola brasileira, de ensino tecnicista, como responsável por impregnar a formação de uma geração de professores, que por sua vez adotou a mesma concepção em sua prática, quer movida pela própria trajetória quer por aderência a um sistema de ensino em que os livros e os manuais didáticos desencorajam a adoção de experiências criativas.

Entre os conteúdos ainda explorados destacam-se os conceitos relativos a elementos de teoria literária, suposta- 
mente necessários para que o aluno "interprete" o texto, o qual invariavelmente é representativo de uma dada estética e deve ser "analisado" sob uma perspectiva histórica. Assim, se alguma prática nova é incorporada pelo professor, logo sua atitude é questionada frente à perspectiva de que seu aluno deverá enfrentar algum vestibular, cujas provas de língua e literatura certamente exigirão um "estudo" sistemático de determinadas obras.

Embora tenha raízes "na tradição escolar brasileira que remontam à pedagogia jesuítica" (AGUIAR; BORDINI, 1988, p. 36), a concepção de aula de literatura foi se adequando, ao longo do tempo, às propostas educacionais, às diretrizes curriculares, sempre ao sabor das mudanças no campo político e social. Assim, a literatura escolarizou-se e os estudiosos têm chegado à conclusão de que este é um mal necessário. Magda Soares afirma que

[...] não há como evitar que a literatura, qualquer literatura, não só a literatura infantil e juvenil, ao se tornar "saber escolar", se escolarize, e não se pode atribuir, em tese, [...] conotação pejorativa a essa escolarização, inevitável e necessária; não se pode criticá-la, ou negá-la, porque isso significaria negar a própria escola. (SOARES, 2003, p. 22, grifo do autor)

Ao expor raciocínios sobre o processo de escolarização a que a literatura está sujeita, Soares conclui: "a questão fundamental das relações entre literatura infantil e escola é que é necessário saber (ou descobrir?) como realizar, de maneira adequada, a inevitável escolarização da literatura" (SOARES, 2003, p. 48).

A par do leitor nato, que continuará lendo, à revelia das circunstâncias reinantes nas salas, há aqueles alunos que só nas bibliotecas escolares encontram oportunidade de conhecer e desbravar o jogo imaginativo que a leitura proporciona, e a partir disso iniciar o percurso que pode torná-los grandes leitores. As duas situações oferecem motivos mais do que razoáveis para se insistir na permanência da literatura no currículo. $\mathrm{O}$ problema está em o que é que se ensina e como se ensina, pois conforme lembrou Soares, há que se buscar a maneira apropriada de abordar o texto literário em sala de aula.

Desde a sua formação, não raras vezes, o professor manteve-se distante das teorias mais recentes sobre a leitura, 
e anseia conhecer ao menos as metodologias que possam subsidiar o seu trabalho. Para adotar uma metodologia adequada ao perfil da sua turma, e escolher estratégias que resultem em aulas bem sucedidas, seria necessário que o professor, em primeiro lugar, fosse ele mesmo um bom leitor, ou ao menos se dispusesse a sê-lo.

O próprio Pennac, chamando a atenção para os embaraços a que a atividade de leitura se atrela, já alertava que de nada adianta as súplicas do professor, se ele também não se entrega aos devaneios da leitura:

É preciso ler! É preciso ler... E se em vez de exigir a leitura, o professor decidisse de repente partilhar sua própria felicidade de ler? A felicidade de ler? O que é isso, felicidade de ler? Questões que pressupõem um bem conhecido cair em si mesmo, na verdade! (PENNAC, 1998, p. 80).

Na condição de efetivo leitor, o professor se tornaria aberto a processos de descoberta e de compreensão não apenas do mundo imaginário em que mergulha, mas do próprio mundo em que vive, e só então pode sentir-se confortável e seguro para fazer uso de instrumentos que tornem a apreciação da leitura mais objetiva. Sua tarefa, afinal, consiste em introduzir o aluno em outras formas de saberes, como lembra Paulo Franchetti: "[...] ela [a literatura] reuniria vários conhecimentos, uniria vários feixes de sentido que são objetos de ciências e disciplinas autônomas, como a história, a filosofia, a psicologia, a sociologia" (FRANCHETTI, 2009, p. 2).

$\mathrm{Na}$ esteira das concepções de Candido e de Todorov, ao amealhar argumentos na defesa do ensino de literatura, Franchetti ainda comenta:

Por meio da literatura aprendemos, sim, muitas coisas. Sobretudo aprendemos a relativizar as certezas, a contemplar o leque das possibilidades de realização (e também das limitações à realização) humana ao longo do eixo temporal ou espacial. (FRANCHETTI ,2009, p. 9)

Compartilhando o mesmo ponto de vista, Carlos Ceia, professor e pesquisador da Universidade Nova de Lisboa, chega a sugerir:

É necessário instituir e concretizar o ensino interdisciplinar, multidisciplinar, pluridisciplinar ou transdisciplinar, 
como se queira, e fazer incluir no estudo literário o estudo da filosofia, da história, da antropologia, da sociologia, da psicologia, da psicanálise, da política, etc., porque o professor de literatura tem que ser um pouco professor de tudo isso, porque a literatura é tudo isso. (CEIA 2004, p. 52)

Como se percebe nesses argumentos, o mergulho no imaginário do livro também agrega o mergulho nas imagens mentais que cada leitor real carrega consigo e aciona no ato da leitura, sejam de experiências pessoais, de conhecimento de mundo, de compartilhamento de informações, ou de emoções e afetos. O uso de metodologias ou estratégias pode auxiliar o professor a explorar esses universos com mais segurança, desde que a leitura em si, de fato, seja priorizada e os encaminhamentos não se transformem em algo mais importante que o contato com o próprio texto.

Vários pesquisadores, convém lembrar, também publicaram suas concepções acerca de novas metodologias que valorizam a recepção do texto pelo aluno, na tentativa de superar o quadro adverso institucionalizado, em que a leitura do jovem sequer é considerada ou em que as ligações, por eles formuladas entre possíveis contextualizações, são desprezadas no momento das considerações sobre o que foi lido. Detectando carências dessa natureza, elaboraram propostas de abordagem, com o objetivo de envolver mais o aluno no ato da leitura, quando podem ser explorados os saberes que o próprio texto veicula ou aqueles a que porventura possa remeter.

Se, enfim, a presença da literatura na sala de aula precisa ser reinventada, para atender a um público constituído em sua maioria de crianças e jovens que só têm acesso a esta modalidade de leitura na escola, se existem metodologias e novas estratégias à disposição dos professores, e se há um processo de conscientização de que se faz a leitura de mundo na leitura do texto, basta uma conjunção de esforços para que a leitura literária possa ser explorada de forma produtiva, enriquecendo a própria caminhada do leitor.

\section{Aula de literatura: sugestão de uma prática}

OGrupo de Pesquisa Literatura e Ensino da UENP - Universidade Estadual do Norte do Paraná tem buscado resgatar, 
há cerca de uma década, os empreendimentos, projetos, práticas que possam ser transformados em sugestões de sequências didáticas, com o objetivo de subsidiar o trabalho do professor em sala de aula. Empenhou-se também em respeitar o contexto em que este docente está inserido e as injunções a que se submete, abrindo possibilidades de atuação e de superação das próprias práticas, dada a reflexão que a experiência pode provocar.

Algumas das práticas investigadas foram reunidas por Boberg e Stopa em Leitura literária na sala de aula: propostas de aplicação (2012), enriquecidas e ilustradas com sugestões de sequências didáticas. No volume em questão constam a Sequência Básica, projetada por Rildo Cosson, em Letramento literário (2006), voltada especialmente para o Ensino Fundamental II; a Proposta Dialógica, que trata das relações dialógicas entre textos literários, seja considerando temas, gêneros diferenciados ou projeto estético, e que estão na base da metodologia concebida por William Roberto Cereja, publicada em Ensino de literatura: uma proposta dialógica para o trabalho com literatura (2005); e ainda a Proposta Rizomática, concebida por integrantes do Grupo de Pesquisa Literatura e Ensino, reunindo concepções da estética da recepção, de rizoma, de transversalidade, e de transdisciplinaridade aplicadas a sequências didáticas que organizam as abordagens de textos literários selecionados.

A sugestão da sequência didática, descrita a seguir, pode integrar uma metodologia escolhida pelo professor ou mesmo compor uma alternativa criada por ele, que melhor se ajuste ao perfil de sua turma.

Dada a diversidade de textos, contemplando modalidades distintas e momentos diferentes da história da literatura de língua portuguesa, a sequência lembra propostas como a dialógica ou a rizomática, fundadas na recepção e nos diálogos entre textos e contextos, ao sabor das impressões expostas e dos rumos das discussões. A prática pode ser aplicada em turmas de alunos que transitam do ensino fundamental ao médio.

O início das conversações informais poderia se dar sobre se ainda hoje são escritas cartas de amor. Embora alguns alunos venham a defender a necessidade de se cultivar o romantismo nas relações, a maioria provavelmente estaria inclinada a apresentar argumentos como: escrever cartas de amor é coisa de gente velha, que ninguém estaria disposto a "pagar este 
mico", que é mais fácil enviar uma mensagem via aplicativos do celular ou deixar recado no Facebook, ou ainda comunicar-se pelo Twiter, quando muito um e-mail, enfim, alegariam que se perdeu o sentido de se escreverem cartas de amor.

Para começar a colher as impressões dos alunos, o professor pode lhes apresentar o poema de Álvaro de Campos, heterônimo de Fernando Pessoa, que se inicia com os versos “Todas as cartas de amor são / Ridículas." É fundamental reservar um tempo para a leitura, seja silenciosa ou oral, em que o aluno possa se entregar à curiosidade do que o texto diz para si. É imprescindível que o professor preste atenção nas reações iniciais dos alunos, suas primeiras sensações, suas dúvidas, suas tentativas de compreensão. $\mathrm{O}$ acolhimento a essas circunstâncias iniciais é que proporcionam o desencadeamento das atividades futuras, com a mesma atenção e os mesmos cuidados, e que promoverão o necessário clima de confiança para que os alunos se envolvam com as leituras.

Em seguida, o professor pode explorar a musicalidade dos versos e as nuanças dos argumentos do sujeito poético, ao promover a leitura oral, especialmente se entregar cada dístico, dos cinco primeiros que compõem o poema, a vozes diferentes, de modo que a leitura ganhe a expressividade da dramatização. Nessas circunstâncias, os leitores percebem com mais clareza que as considerações do eu lírico sobre as cartas de amor variam a todo instante, originando vertentes de interpretação distintas, até o momento em que, numa reflexão final, chega à conclusão de que tanto o sentimento amoroso, como a tentativa de expressá-lo por palavras são igualmente "esdrúxulos", já que o amor é indefinível.

Para demonstrar essa conviç̧ão traduzida pelos poetas, pode-se incluir a leitura de dois sonetos já conhecidos dos alunos por meio dos livros didáticos: “O amor é fogo que arde sem se ver", de Camões, e "Soneto do amor maior", de Vinícius de Moraes, com o propósito de estabelecer contrapontos entre os três poemas. Para cada poema, deve-se preservar o seu tempo de leitura. Vale investir especialmente na leitura oral, para o afloramento das percepções de cada leitor, e no estabelecimento de paralelos entre os "eus-líricos", que se veem sem condições de determinar o estado em que se encontram, ao sabor das 
emoções discrepantes provocadas pelo sentimento. Por tratar-se de uma experiência comum a todos, o envolvimento dos alunos com o tema abordado exigirá do professor o papel de mediador dos relatos pessoais que certamente serão invocados na altura em que as apreciações ganharem fôlego.

Lançado o desafio de se pensar em cartas de amor como veículo de sentimentos e de emoções entre apaixonados, é possível introduzir a leitura de um trecho da segunda carta de amor, de Sóror Mariana Alcoforado (2011). Um véu de mistério, como se conta, envolve a história da religiosa, que viveu no Convento de Nossa Senhora da Conceição, em Beja, Portugal, no final do século XVII, a quem são atribuídas cinco cartas dirigidas a um oficial francês, e que ficaram conhecidas como "Cartas portuguesas". A segunda carta contém o relato das circunstâncias que ligam a freira ao objeto de seu amor: o rapaz é militar, havia servido o exército francês muito próximo ao convento, conheceram-se e, depois de seduzi-la, com seu consentimento, afastou-se dela ao retornar a sua pátria. Nessas condições, embora já esteja caracterizado o abandono, a religiosa se esforça para crer que o seu amado lhe dará notícias, e se prostra submissa, conforme se caracterizava tanto a relação social quanto amorosa no contexto histórico e cultural europeu do final do século XVII e início do XVIII.

É possível recuperar nessa leitura, caso o professor queira enveredar por este caminho, particularidades da tradição literária que se acentuaram ao longo do tempo, desde as cantigas de amigo medievais: a angústia do abandono, a esperança de que a situação se reverta, a crença de que o amor vivido compensa todas as amarguras, a valorização do sentimento amoroso, mesmo num estado de completa submissão. Essas características podem explicar ao leitor jovem como o tratamento dado a tais circunstâncias amorosas ganhou roupagens novas ao longo do tempo, e foram recriadas em outros gêneros textuais, incluindo os virtuais, ou adaptadas aos mais recentes recursos de mídia, travestidos em novelas e séries da televisão, ou filmes e jogos. O imaginário despertado pelas leituras dos textos até então lidos é atravessado pelo imaginário que os demais contextos reverberam e os diálogos mentais se multiplicam e podem ser expressados pelos estudantes. 
Eis os primeiros passos para que de fato se envolvam com as leituras efetuadas.

Por sua vez, conhecer o contexto histórico e cultural do período em que viveu a suposta autora das cartas, os poucos traços do seu perfil, que a história literária registrou, e especialmente a força de um discurso amoroso vibrante e ousado para o seu tempo, pode motivar os alunos a se interessarem por textos autobiográficos, ou por mais histórias de relacionamentos amorosos em que as cartas estejam presentes.

Seria o caso, por exemplo, de introduzir, em próxima oportunidade, a leitura de outro texto ilustrativo da literatura portuguesa, a novela passional Amor de perdição, de Camilo Castelo Branco. Da trama fazem parte as cartas trocadas entre os adolescentes, tão importantes em alguns momentos da narrativa, que chegam a ter a função de narradoras. Algumas dessas cartas podem ser objeto de apreciação mais fecunda, especialmente aquelas em que os namorados fazem planos para o futuro, em contraponto com a última carta de Tereza, síntese dos sofrimentos dos dois amantes, e de despedida dos sonhos e da vida. Outros elementos podem ser observados pelo professor, caso faça questão de explorar a estética romântica para não fugir do programa curricular: as peculiaridades do ultrarromantismo presentes no texto, como o fatalismo, o pessimismo, a idealização do amor e a evasão para a morte, último reduto da busca pela felicidade inatingível. A tônica dessas cartas revela a busca pela realização do amor impossível, tão comum na tradição literária, desde os casais de personagens consagrados, como Bernardo e Eloisa e Romeu e Julieta, eles também escritores de cartas de amor.

A propósito, se a leitura da novela camiliana não resultar completa, e apenas as cartas tornarem-se objeto de apreciação, é tempo de lembrar outra recomendação de Pennac: os direitos imprescritíveis do leitor, dentre eles, o de não ler, de pular páginas, de não terminar um livro, porque "se quisermos que filho, filha, que os jovens leiam, é urgente lhes conceder os direitos que proporcionamos a nós mesmos" (PENNAC,1998, p. 140).

Encerrando o percurso empreendido, que revelou a escrita de emoções tão intensas e contraditórias, seria interessante fazer a leitura de uma pequena crônica de Moacyr Scliar, 
"Cartas de amor", com o propósito de conhecer nova vertente de interpretações junto ao rol dos textos já lidos. Eis o texto:

Eu era aluno do Júlio de Castilhos e estudava à tarde (as manhãs, naquela época, estavam reservadas às turmas femininas). Um dia cheguei para a aula, coloquei meus livros na carteira e ali estava, bem no fundo, um papel cuidadosamente dobrado. Era uma carta; dirigida não a mim, mas "ao colega da tarde". E era uma carta de amor. De amor não; de paixão. Paixão fogosa, incontida, transbordante, a carta de uma alma sequiosa de afeto. À qual o jovem escritor não teve a menor dificuldade de responder.

Iniciou-se assim uma correspondência que se prolongou pelo ano letivo, não se interrompendo nem com as provas, nem com as férias de julho. À medida que o ano ia chegando a seu fim, os arroubos epistolares iam crescendo. Cheguei à conclusão de que precisava conhecer a minha misteriosa correspondente, aquela bela da manhã que me encantava com suas frases.

Mas... Seria realmente bela? A julgar pela letra, sim; eu até a imaginava como uma moça esguia, morena, de belos olhos verdes. Contudo, nem mesmo os grandes especialistas em grafologia estão imunes ao erro, e um engano poderia ser trágico. Além disto, eu já tinha uma namorada que não escrevia, mas era igualmente fogosa.

Optei, portanto, pelo mistério, pelo "nunca te vi, sempre te amei". A minha história de amor continuou somente na fantasia. Que é o melhor lugar para as grandes histórias de amor. (SCLIAR, 1996, p. 85-86)

Tal como nas leituras anteriores, deve-se guardar o tempo necessário para a colheita das impressões dos alunos. A leitura da crônica tem o teor leve e muito próximo do cotidiano, permitindo que o aluno constate a presença de elementos literários distintos daqueles que permearam os textos anteriores, como o tema vinculado à tradição literária ou com características formais rígidas, conforme se verifica no soneto, ou ainda com acentuadas preocupações estéticas, como se vê no texto de Camilo Castelo Branco.

A linguagem coloquial, de caráter intimista, os personagens retratados como pessoas comuns, vivendo uma situação corriqueira, dentro de uma escola - o próprio ambiente vivido pelos alunos - a natureza fugaz e banal do episódio narrado, mas que provoca reflexão justamente por levantar questiona- 
mentos próprios do adolescente, por evidenciar os contrastes do mundo em que vivemos e as escolhas que fazemos, tudo isso revela ao jovem leitor que ele pode encontrar na literatura uma extensão do seu mundo real e por meio dela conhecer o próprio mundo.

Recuperando as opiniões de Todorov, Pennac, Franchetti e Ceia, citados anteriormente, vemos que a leitura literária, no caminho oposto ao da sua escolarização equivocada, pode ser a patrocinadora de experiências estéticas e emotivas ímpares, desde que o professor também seja leitor e atue como mediador das leituras com sensibilidade, explorando os sentidos que os textos oferecem. Assim, além de facultar ao aluno um passeio pela tradição literária, de dar a conhecer algumas peculiaridades estéticas, de recuperar as produções de autores consagrados, o professor ainda pode observar, especificamente a partir da seleção feita: a variedade dos pontos de vista dos "escreventes" das cartas de amor e dos "narradores" dessa experiência, vinculada ou não aos contextos históricos e culturais em que os textos foram concebidos, a manifestação das emoções pelos personagens ou narradores, os questionamentos que levantam acerca dos próprios sentimentos expostos, o contraste evidenciado entre os sentimentos de amor e paixão, e até mesmo a manifestação do erotismo em alguns trechos.

Encerradas as atividades de confronto entre os textos - circunstâncias que podem demandar aulas seguidas - é o momento de reunir mais uma vez as impressões dos alunos quando se submeteram à condição de protagonistas dos episódios narrados ou poetizados. Tal experiência naturalmente vem à tona, porque é estimulada no ato da leitura e na apreensão do literário, quando se buscam os sentidos do texto, bastando ao professor administrar os relatos e as opiniões despertadas. É preciso considerar as pontes que existem entre a percepção do prazer estético e a exposição das próprias emoções e ainda valorizar as ligações que os alunos empreendem. São experiências indissociáveis no ato da leitura, e apesar de a escola ignorá-las na apreciação do texto, mostram-se essenciais para o bom êxito de uma aula de literatura, porque se prestou mais atenção aos sentidos que os textos têm para cada aluno, mesmo que a atividade parta de uma seleção de textos conduzida pelo professor e que questões curriculares ainda sejam reproduzidas. 
A título de ilustração do percurso da leitura dos textos selecionados, e das possíveis ligações que os alunos podem empreender, sob a diligência do professor, foi composto o desenho abaixo:

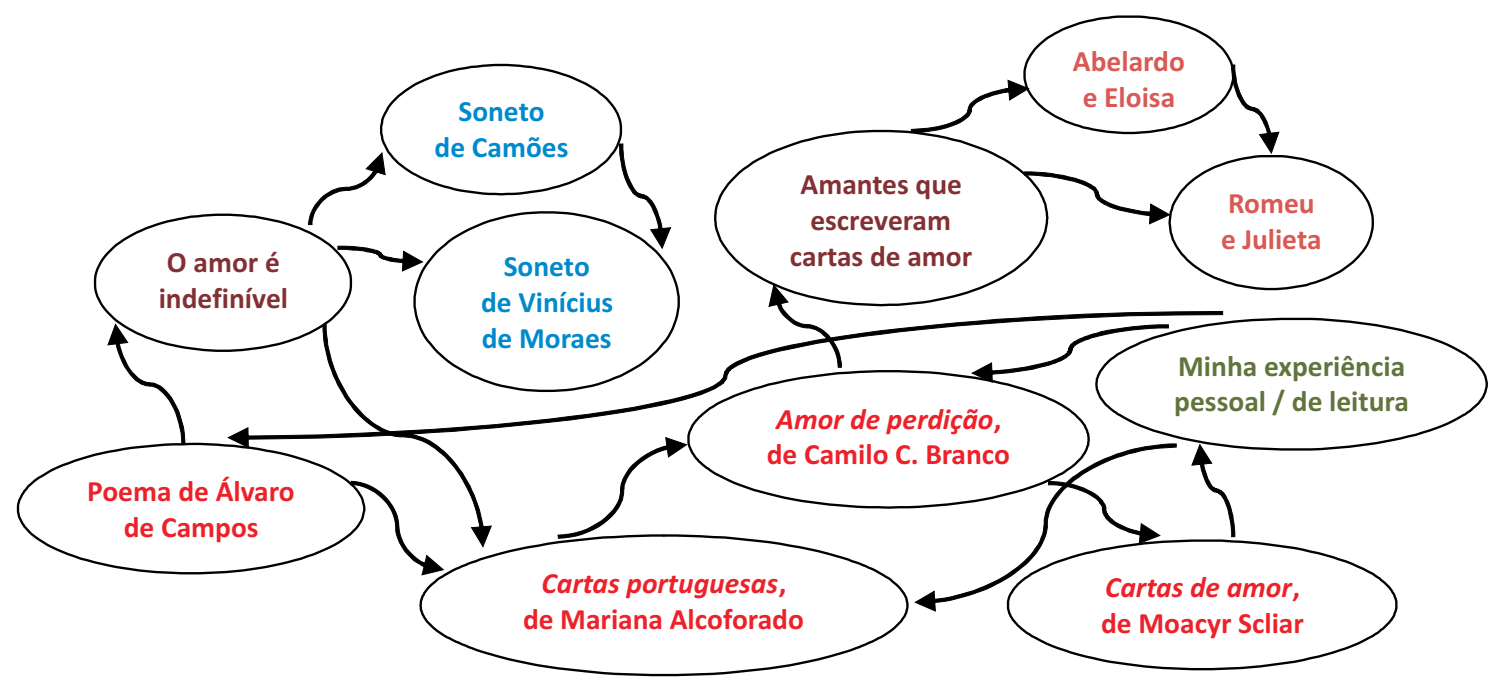

Como se vê, trata-se de um percurso de leitura não linear, portanto, não convencional, muito próximo de propostas metodológicas como a dialógica ou a rizomática. É evidente a riqueza cultural, literária, estética, emotiva e mesmo educacional dele decorrente, especialmente quando o professor é leitor e está sempre disposto a entregar-se ao aprimoramento.

\section{Considerações finais}

O abandono de práticas convencionais de leitura e interpretação, direcionando energias para o acolhimento das considerações pessoais dos alunos, o aproveitamento dos saberes que o texto revela, em contraponto com os múltiplos conhecimentos com os quais ele possa dialogar, além do cultivo do prazer estético, são providências simples, quase intuitivas, que poderiam ser adotadas pelos docentes. O exercício dessa prática, numa evidente demonstração de que se busca o convívio com a literatura sem as restrições da disciplinarização, traria ao docente a segurança para o necessário mergulho no ato da 
leitura, especialmente porque estaria à mercê de suas próprias indagações e percepções, e entregue a uma experiência única de franco diálogo com o texto.

No momento em que experiências pessoais e emoções são evocadas, a leitura atinge o campo das significações, da verdadeira identificação entre leitor e o texto. É a oportunidade ímpar lembrada por Antonio Candido, em que se dá a fruição da leitura, como um direito inalienável: "A literatura desenvolve em nós a quota de humanidade na medida em que nos torna mais compreensivos e abertos para a natureza, a sociedade, o semelhante" (CANDIDO, 1995, p. 249).

Se o ensino da literatura fosse efetivamente compreendido como a oportunidade que a escola pode oferecer para o exercício consciente de nossa humanização, talvez tivéssemos mais leitores e mais amantes da leitura literária, com todas as implicações daí decorrentes: um leitor mais crítico, sujeito dos seus próprios argumentos e ponderações, um imaginário mais enriquecido, criativo e atuante, e talvez, em breve prazo, uma sociedade mais esclarecida.

\section{REFERÊNCIAS}

AGUIAR, Vera Teixeira de; BORDINI, Maria da Glória. A formação do leitor: alternativas metodológicas. Porto Alegre: Mercado Aberto, 1988.

ANDRADE, C. D. de. A educação do ser poético. JB, Caderno B, 20/07/1974, p. 5.

BOBERG, Hiudéa T. Rodrigues; STOPA, Rafaela. Leitura literária na sala de aula: propostas de aplicação. Curitiba: CRV, 2012. BRANCO, Camilo Castelo. Amor de perdição. São Paulo: Ática, 1997.

CAMÕES. Amor é fogo que arde sem se ver. Rio de Janeiro: Ediouro, 1997.

CANDIDO, Antonio. Direito à literatura. In: Vários escritos. 3. ed. São Paulo: Duas Cidades, 1995.

CARTAS portuguesas atribuídas a Mariana Alcoforado. Trad. Eugénio de Andrade. Lisboa: RTP, 1980. 
CEIA, Carlos. A literatura ensina-se? Lisboa: Edições Colibri, 2004. CEREJA, William Roberto. Ensino de literatura: uma proposta dialógica para o trabalho com literatura. São Paulo Atual, 2005. COSSON, Rildo. Letramento literário. São Paulo: Contexto, 2006. FRANCHETTI, Paulo. Ensinar literatura para quê? Disponível em http://maisdesenredos.blogspot.com/2011/01/ensinarliteratura-para-que.html. Acesso em 20/02/2011.

GRUPO DE PESQUISA Literatura e Ensino. Disponível em lattes.cnpq.br/9423974341180731.

MORAES, Vinícius de. Soneto do amor maior. In: FERRAZ, Eucanaã. Caminho para a distância. São Paulo: Companhia das Letras, 2008.

PENNAC, Daniel. Como um romance. 4. ed. Trad. Leny Werneck. Rio de Janeiro: Rocco, 1998.

PESSOA, Fernando. Obra poética. Organização, introdução e notas de Maria Aliete Galhoz. Rio de Janeiro: Editora José Aguilar, 1960.

ROUXEL, Annie. Aspectos metodológicos do ensino da literatura. In: DALVI, Maria Amélia e outros. Leitura de literatura na escola. São Paulo: Parábola, 2013.

SCLYAR, Moacyr. Cartas de amor. In: Minha mãe não entende nada. 2. ed. Porto Alegre, L\&PM, 1996. SOARES, Magda. A escolarização da literatura infantil e juvenil. In: EVANGELISTA, Aracy Alves Martins et alli. A escolarização da leitura literária. 2. ed. Belo Horizonte, 2003.

TODOROV, Tzvetan. A literatura em perigo. Trad. Caio Meira. Rio de Janeiro, DIFEL, 2009. 


\section{Abstract \\ The reader subject and its human condition in the approach of the literary text in secondary education}

This article aims to discuss some issues related to the failure of the teaching of literature in school, especially for teenagers, observing that the traditional pattern can and should be replaced by an approach of the literary text that prioritizes the involvement of the reader subject with its personal reading, that enriches their impressions of the undertaken reading in the light of new theories still contributory of aesthetics of reception. To illustrate the proposal, we present a didactic sequence, which can be appropriate to teaching work, even if he/she follows current traditional programs.

Keywords: Teaching literature; Reader subject; Didactic sequence. 